\title{
Hydrodynamics and photosynthesis performance of Chlorella fusca (Chlorophyta) grown in a thin-layer cascade (TLC) system
}

\author{
Celia G. Jerez ${ }^{1, *}$, Enrique Navarro ${ }^{2}$, Irene Malpartida ${ }^{1}$, Rosa M. Rico ${ }^{1}$, \\ Jiří Masojídek $^{3,4}{ }^{\text {, Roberto Abdala }}{ }^{1}$, Félix L. Figueroa ${ }^{1}$ \\ ${ }^{1}$ Departamento de Ecología, Facultad de Ciencias, Universidad de Málaga, Campus Universitario de Teatinos s/n, \\ 29071 Málaga, Spain \\ ${ }^{2}$ Pirenaic Institute of Ecology (CSIC), Campus de Aula Dei, Avda. Montañana 1005, 50059 Zaragoza, Spain \\ ${ }^{3}$ Laboratory of Algal Biotechnology, Institute of Microbiology, Academy of Science, Opatovický mlýn, 37981 Tr̆ebon̆, \\ Czech Republic \\ ${ }^{4}$ Faculty of Science, University of South Bohemia, 37005 České Budějovice, Czech Republic
}

\begin{abstract}
The thin-layer cascade (TLC) system is an open system for microalgae cultivation composed of a retention tank connected by pump and pipes to a horizontal exposed area that consists of an upper basin and a TLC. Light and hydrodynamics are different among compartments, so overall photosynthetic activity can be influenced by the retention time of the cells in each compartment. We established 2 settings with different retention times in the cascade and tank to compare the photosynthetic activity of Chlorella fusca (Chlorophyta) among compartments. Changes in the retention time were achieved using 2 layer thicknesses in the cascade: 8 and $18 \mathrm{~mm}$. Retention time in the cascade represented about 16 and $34 \%$ of the duration of a whole system cycle when H1 (8 $\mathrm{mm}$ thickness) and H2 (18 mm thickness) units, respectively, were used. These retention periods were lower than those in the tank (67 and $49 \%$, respectively) but higher than those in the basin (12\% for both $\mathrm{H} 1$ and H2). Photosynthetic activity was measured in situ as relative electron transport rate (rETR) using a pulse-amplitude modulated fluorometer. In both setups, the highest rETR was reached in the cascade. The increase of the layer thickness was a good option to avoid photoinhibition. We suggest estimating the mean rETR of the whole system considering the retention time, since it can better reflect overall growth because it takes into account the time that the cells spend in each compartment. These results are useful for optimization of photosynthetic activity and growth of outdoor microalgae mass cultures in TLCs for biotechnological purposes.
\end{abstract}

KEY WORDS: Chlorella fusca - In vivo chlorophyll fluorescence $\cdot$ Photosynthesis · Productivity · Relative electron transport rate $\cdot$ Thin-layer cascade $\cdot$ Microalgae $\cdot$ Photobioreactor

\section{INTRODUCTION}

Microalgae have been produced on a commercial scale since the 1950s. The biomass has been used as a human nutrition additive, as a supplement to animal feeds (Muller-Feuga 2000), in wastewater treatment applications (Mulbry et al. 2008, Chinnasamy et al. 2010, Li et al. 2011) and as a source of secondary

*Corresponding author: cgjerez@uma.es metabolites with cosmetic and nutraceutical applications (Spolaore et al. 2006, Markou \& Nerantzis 2013). Recently, microalgae cultivation has been considered as a potential source for different types of renewable biofuels: biodiesel or bioethanol derived from microalgal oil or starch (Brányiková et al. 2011) and methane produced by anaerobic digestion or biohydrogen (Chisti 2007). However, large-scale culrestricted. Authors and original publication must be credited. 
tivation of microalgae is still limited by engineering and biological factors which are essential to attain a cost-effective system; light use efficiency to achieve high production rates and harvesting and processing of microalgal biomass must be improved to reach an efficient use of the energy and nutrient sources. The imperative for most microalgal production plants will be the production of large quantities of biomass per area over short time periods using a cultivation system easy to scale up to many hectares (Grobbelaar 2010).

Two basic approaches are currently used for largescale microalgae production: open and closed systems (the so-called photobioreactors), where the latter implies that there is no direct contact between the culture and the atmosphere. The advantages and disadvantages of both systems have been discussed in several reports (Pulz 2001, Grobbelaar 2009a, Tredici 2010). Although closed systems provide more accurate control of culture parameters and they are often crucial to guarantee the availability of inoculum, most of the large commercial systems used today are open systems, mainly open raceway ponds and thin-layer cascade (TLC) systems (Borowitzka 1999, Pulz 2001, Tredici 2010, Masojídek et al. 2011, Grobbelaar 2012).

The first microalgae production facility based on TLC systems started in the 1960s in Tr̆ebon (Czech Republic) (Šetlík et al. 1970), although improved units are currently being used (Masojídek \& Prášil 2010). TLC systems are based on the circulation of a very thin layer of microalgal suspension $(<10 \mathrm{~mm})$ over a flat, inclined surface exposed to sunlight. Therefore, as the light path is very short, light use is very efficient, and high biomass densities (25 to $35 \mathrm{~g}$ $1^{-1}$ ) can be achieved (Grobbelaar 2009a, Masojídek et al. 2011).

Light is one of the most critical factors for microalgal production, as the growth rate depends on the light availability within the cultivation system and the light regime applied. In addition to the climatic conditions of the location and the orientation of the units, the light regime is also determined by the time courses of the cells in areas with different irradiance levels (Grima et al. 2010). In TLC systems, which are comprised of various compartments, the cells can experience a wide range of light absorption levels because of the very different light penetration among sections. In a system cycle, the system hydrodynamics will determine the time the cells spend in each of these areas (residence time) and therefore the light regime. Consequently, if the system hydrodynamics change (e.g. pump velocity, retention time, layer thickness), the daily light absorption will be affected.

Light regime is not constant in outdoor conditions as it presents diurnal and annual variations due to changes in solar radiation. These changes produce light:dark cycles of different frequency, which become of great importance since they affect biomass productivity. In outdoor mass production systems, cells are exposed to 3 light:dark regimes (Grobbelaar 1994): (1) low-frequency fluctuations (hours to days), determined mainly by diurnal and seasonal variations of incident irradiance; (2) medium-frequency fluctuations (seconds to minutes), related to the system design, which in TLC systems depends on the residence times in the illuminated and dark compartments (pump, tubes and tank); and (3) high-frequency fluctuations, in the range of tens and hundreds of milliseconds, which take place in the microalgal layer where cell movement is fast because of its turbulent regime and short optical cross section. High-frequency fluctuations have been proven to increase light efficiency and productivity (Kok 1953, Terry 1986, Grobbelaar et al. 1996, Grobbelaar 2009b, 2010, Sforza et al. 2012), as such short durations match the turnover of the photosynthetic apparatus, which is suggested to be about $10 \mathrm{~ms}$ (Falkowski et al. 1985, Dubinsky et al. 1986). In contrast, mediumfrequency fluctuations are related to the exposed surface to total volume $(S / V)$ ratio of the cultivation unit; higher biomass productivities are achieved in units with high ratios (Masojídek et al. 2011).

The development of non-intrusive methodologies such as in vivo chlorophyll fluorescence techniques (pulse-amplitude modulation, PAM) enables rapid and sensitive measurements of changes in the physiological status of plants subjected to different environmental or culture systems (Schreiber et al. 1986), providing physiological information on microalgae under in situ growth conditions (Kromkamp et al. 2008). In vivo chlorophyll a fluorescence measurements have been widely used to estimate photosynthetic activity and primary productivity (Genty et al. 1989, Torzillo et al. 1996, Baker 2008, Suggett et al. 2010, Figueroa et al. 2013). When applied to microalgal cultures, these measurements reflect the performance of PS II photochemical processes and, thus, their photosynthetic activity and growth.

In this study, we describe the hydrodynamics (based on retention time) and photosynthetic performance of Chlorella fusca in the different compartments of a TLC system (upper basin, cascade area and retention tank) under varying layer thicknesses in the cascade. We aim to compare the relative electron transport 
rate (rETR) of the culture in each compartment under different hydrodynamic conditions given by changes in the retention time of the cascade and tank. The system described in this study was used as the experimental unit at the 9th International Group for Aquatic Primary Productivity (GAP) Workshop ('Influence of the pulsed-supply of nitrogen on primary productivity in phytoplankton and marine macrophytes: an experimental approach') by Working Group 2, Algal Biotechnology (see Ihnken et al. 2014, Malpartida et al. 2014 both this Theme Section).

\section{MATERIALS AND METHODS}

\section{Species and culture conditions}

Laboratory culture of the microalga Chlorella fusca (Shihira \& Krauss, deposited in the Culture Collection of Marine Microalgae, Marine Sciences Institute of Andalusia [ICMAN-CSIC], Cádiz, Spain, and in the Spanish Bank of Algae [BEA]) was grown in Bold's Basal Medium fortified with 3-fold nitrate content and the addition of vitamins (3N-BBM-V) (Bischoff \& Bold 1963, Andersen et al. 2005) under irradiance of $150 \mu \mathrm{mol}$ photons $\mathrm{m}^{-2} \mathrm{~s}^{-1}$ at $25^{\circ} \mathrm{C}(12 \mathrm{~h}$ light:12 $\mathrm{h}$ dark). Then, at certain biomass density $(0.4$ to $0.5 \mathrm{~g} \mathrm{l}^{-1}$ ), the culture was transferred to outdoor systems.

The experiment was carried out in September 2011 and the measurements were taken on the eighth and ninth days after inoculation, when the biomass density had reached $1.65 \mathrm{~g} \mathrm{l}^{-1}$. Under outdoor conditions, macronutrients $\left(\mathrm{NaNO}_{3}, \mathrm{MgSO}_{4}\right.$ and $\left.\mathrm{KH}_{2} \mathrm{PO}_{4}\right)$ were added once a day using common farming fertilizers (to reduce costs) according to the composition of the $3 \mathrm{~N}-\mathrm{BBM}-\mathrm{V}$ medium. Micronutrients were added $\left(60 \mu \mathrm{l}^{-1}\right)$ using a commercial mixture (Welgro Hydroponic, Comercial Química Massó). The microalgal suspension was circulated day and night to keep the same conditions during the day and night. The diurnal cycle was about $14 \mathrm{~h}$ light: $10 \mathrm{~h}$ dark in southern Spain at this time of the year. The temperature of the culture was measured using a HOBO Pro v2 water temperature logger (U22-001) placed in the basin. During the experiment, it ranged between $30^{\circ}$ (day) and $21^{\circ} \mathrm{C}$ (night). The pHvalue was controlled manually and maintained between 7.2 and 7.6 by injection of pure $\mathrm{CO}_{2}$. The average daily integrated irradiance values were 8351.0, 1097.5 and $53.3 \mathrm{~kJ} \mathrm{~m}^{-2}$ for photosynthetically active radiation (PAR, 400 to $700 \mathrm{~nm}$ ), UVA radiation (320 to $400 \mathrm{~nm}$ ) and UVB radiation (280 to $320 \mathrm{~nm}$ ), respectively.

\section{TLC system}

The outdoor cultivation unit used in this study was a TLC system built of fiberglass and was located in Málaga, Spain $\left(36^{\circ} 43^{\prime} \mathrm{N}, 4^{\circ} 25^{\prime} \mathrm{E}\right)$. The unit consists of 4 parts: basin, cascade plate, tank and piping (with a centrifugal pump, Niper, ESPA) (the latter 2 represent dark volume). The dimensions and area of each part are described in Fig. 1. Microalgal suspension flows in a thin layer (8 or $18 \mathrm{~mm}$ ) from the basin (upper part of the cultivation surface, section $\mathrm{A}$ in Fig. 1) over a sloping cascade (2\%) exposed southwards (B). After exposure on the cultivation surface of the cascade, the suspension is collected in a retention tank (C), where it is mixed by an aeration system and pumped back to the basin via tubes (D) connected to the bottom of the tank.

The thickness of the layer in the cascade can be changed from 8 (H1) to $18 \mathrm{~mm}(\mathrm{H} 2)$ by placing a rectangular piece of fiberglass at the end of the cascade, as a baffle, before the suspension flows into the tank. In this way, the volume of culture in the tank and in the cascade is modified, as well as the retention time in both sections (the dark volume and the volume in the basin are constant). Thus, studies focusing on the photosynthetic performance and growth of the system can be conducted considering different retention times and bio-optical conditions in the cascade and in the tank.

1.
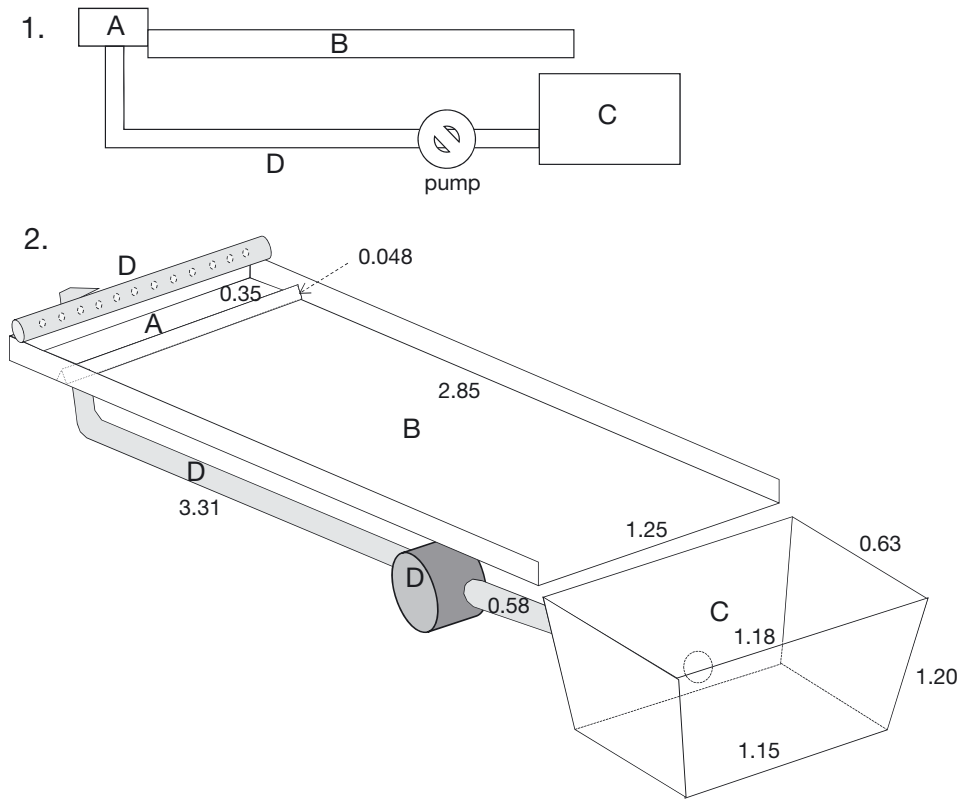

Fig. 1. Side and perspective view of the thin-layer cascade system. A: upper basin, B: cascade, C: tank and D: tubes. Numbers indicate dimensions $(\mathrm{m})$ 


\section{Hydrodynamics characterization: retention time}

The retention time $(\tau, \mathrm{s})$ of a fluid in a vessel is a variable of vital importance in the design of photobioreactors (Ghirelli \& Leckner 2004), which is calculated as the ratio $V / Q$ between the volume and the flow rate $\left(Q, 0.00252 \mathrm{~m}^{3} \mathrm{~s}^{-1}\right)$. In this study, $V\left(\mathrm{~m}^{3}\right)$ and $S / V$ ratio $\left(\mathrm{m}^{-1}\right)$ were determined using the dimensions of each section, and $\tau$ was calculated as described above.

Different experimental procedures can be applied to measure the retention time in the system. One of them is called the 'pulse experiment', in which a pulse of tracer is introduced in the inlet to the domain, while the tracer concentration is measured continuously at a given point. In this study, $\mathrm{NaCl}$ was used as a tracer, but instead of its concentration, changes in the water conductivity were measured. Thus, the residence time is estimated as:

$$
\tau=\frac{\int_{0}^{\infty} C \cdot t \cdot \mathrm{d} t}{\int_{0}^{\infty} C \mathrm{~d} t}
$$

where $C$ is the water conductivity $\left(\mu \mathrm{S} \mathrm{cm} \mathrm{cm}^{-1}\right)$ and $t$ is the time (s) elapsed since the injection of the tracer. Measurements were made by adding a solution of $\mathrm{NaCl}$ to the basin and measuring the conductivity at the end of the cascade outlet (sections $A$ and $B$, respectively; see Figs. 1 \& 2). The

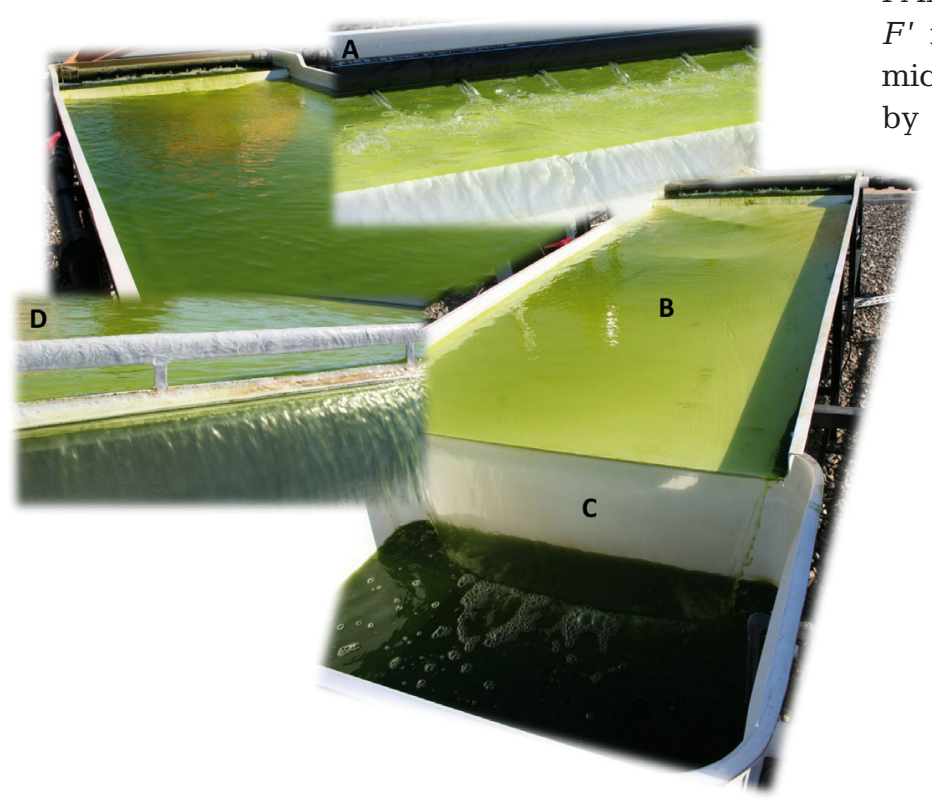

Fig. 2. Different compartments of the thin-layer cascade. (A) Upper basin, (B) cascade: $8 \mathrm{~mm}$ (H1) and $18 \mathrm{~mm}$ (H2), (C) tank and (D) detail of the baffle used to increase the height of the layer in the cascade same was done for the tank and the dark phase (sections $\mathrm{C}$ and $\mathrm{D}$; see Figs. 1 \& 2) by adding the $\mathrm{NaCl}$ solution in the tank and measuring the conductivity in the basin. The multiparameter portable instrument Hi9829 (Hanna Instruments) was used for the conductivity measurements.

\section{Irradiance and chlorophyll fluorescence measurements}

Both irradiance and chlorophyll fluorescence were measured in parallel in the basin, cascade and tank to compare the photosynthetic performance between different system sections.

PAR was measured inside the culture using a spherical quantum microsensor (3.7 $\mathrm{mm}$ diameter) (US-SQS/L, Walz) for measurements in the basin and cascade, whereas in the tank, another spherical quantum sensor (8 $\mathrm{mm}$ diameter) (Zemoko) was used. Intercalibration between both sensors was conducted taking as reference the data of the US-SQS/L spherical quantum sensor.

The effective quantum yield $\left(\Delta F / F_{\mathrm{m}}{ }^{\prime}\right)$ was calculated according to Schreiber et al. (1995):

$$
\Delta F / F_{\mathrm{m}}{ }^{\prime}=\left(F_{\mathrm{m}}{ }^{\prime}-F^{\prime}\right) / F_{\mathrm{m}}{ }^{\prime}
$$

where $F_{\mathrm{m}}$ ' is the maximal fluorescence induced by a saturating flashlight from the halogen lamp (DivingPAM, Walz) at irradiance $>3500 \mu \mathrm{mol} \mathrm{m} \mathrm{m}^{-2} \mathrm{~s}^{-1}$, and $F^{\prime}$ is the actual fluorescence yield in light-adapted microalgae. Recommendations for nomenclature given by Kromkamp \& Forster (2003) were followed for chlorophyll fluorescence measurements.

Both measurements, irradiance of PAR and $\Delta F / F_{\mathrm{m}}{ }^{\prime}$, were conducted in situ by introducing the spherical quantum sensor and the light guide of the fluorometer into the basin and the cascade at 3 and $6 \mathrm{~mm}$ depth, respectively $(\mathrm{n}=5)$. The measuring depth chosen in the cascade $(3 \mathrm{~mm}$ ) was the average depth (total depth was $6 \mathrm{~mm}$ ), whereas the measuring depth chosen in the basin was $6 \mathrm{~mm}$. In the tanks, where the total depth was 12 or $15 \mathrm{~cm}$ (depending on whether $\mathrm{H} 1$ or $\mathrm{H} 2$, respectively, was applied in the cascade), the measurements were done every $50 \mathrm{~mm}$ from the surface to the bottom ( $\mathrm{n}=5$ at each depth). A depth profile of the $\mathrm{rETR}\left(\Delta F / F_{\mathrm{m}}{ }^{\prime} \times E\right)$ was calculated by multiplication of $\Delta F / F_{\mathrm{m}}{ }^{\prime}$ and the irradiance $(E)$ at each depth, from which an average rETR in the tank was calculated. Results were expressed as mean \pm SD. 
Table 1. Hydrodynamics data. Area and volume of the different compartments of the system. Values shown indicate culture layers of 8 and $18 \mathrm{~mm}$ (H1 and H2, respectively). Total values consider the whole system, while the exposed area only takes into account the basin and the cascade

\begin{tabular}{|c|c|c|c|c|c|c|c|}
\hline & \multirow{2}{*}{$\begin{array}{c}\text { Area } \\
\left(\mathrm{m}^{2}\right)\end{array}$} & \multicolumn{3}{|c|}{ Culture layer: 8 mm (H1) } & \multicolumn{3}{|c|}{ Culture layer: 18 mm (H2) } \\
\hline & & $\begin{array}{l}\text { Volume } \\
\text { (l) }\end{array}$ & $\begin{array}{l}\text { Retention } \\
\text { time (s) }\end{array}$ & $\begin{array}{c}\text { Retention } \\
\text { time }(\%)\end{array}$ & $\begin{array}{l}\text { Volume } \\
\text { (l) }\end{array}$ & $\begin{array}{l}\text { Retention } \\
\text { time }(\mathrm{s})\end{array}$ & $\begin{array}{c}\text { Retention } \\
\text { time }(\%)\end{array}$ \\
\hline Basin & 0.44 & 21.00 & 8.34 & 11.80 & 21.00 & 8.34 & 11.78 \\
\hline Cascade & 3.56 & 28.50 & 11.32 & 16.01 & 60.56 & 24.06 & 33.98 \\
\hline Tank & 0.72 & 118.82 & 47.21 & 66.74 & 86.94 & 34.55 & 48.79 \\
\hline Dark volume & 0.49 & 9.70 & 3.86 & 5.45 & 9.70 & 3.86 & 5.45 \\
\hline Total & 5.22 & 178.02 & 70.74 & 100.00 & 178.21 & 70.81 & 100.00 \\
\hline Exposed area & 4.00 & 49.50 & 19.67 & 27.81 & 81.56 & 32.41 & 45.77 \\
\hline
\end{tabular}

\section{RESULTS}

\section{Hydrodynamic characterization: retention time}

The area and volume of the different system sections are shown in Table 1 . The system has an area of $5.2 \mathrm{~m}^{2}$, of which $4 \mathrm{~m}^{2}$ are exposed to light (basin and cascade). To operate the system at its maximum $S / V$ ratio, the working volume was adjusted to the minimum required for pump functioning (178 l). Therefore, system $S / V$ is $22.5 \mathrm{~m}^{-1}$ considering the light-exposed area and the total culture volume. There are 2 possible configurations of the system, depending on whether the 'baffle' (rectangular piece of fiberglass) is placed (or not) at the end of the cascade. Because of the system design, this element changes the volume and the retention times in the cascade and in the tank, while they remain constant in the basin and in the dark volume (21 l, $8.3 \mathrm{~s}$ and $10 \mathrm{l}, 3.8 \mathrm{~s}$, respectively). A whole cycle took $70.6 \mathrm{~s}$, of which the cells spent $19.6 \mathrm{~s}(28 \%)$ in the exposed area and $47.2 \mathrm{~s}(67 \%)$ in the tank when the height of the cascade was $8 \mathrm{~mm}$. Thus, in these conditions, the tank represented the largest section and therefore the one in which the cells would spend more time. In contrast, the cascade represented only $29 \mathrm{l}$ with a residence time of $11 \mathrm{~s}$ $(16 \%)$, so prolonging its retention time is desirable, as this is the compartment where higher productivities are supposed to be achieved because of its short light path. For that, the layer thickness was increased from 8 to $18 \mathrm{~mm}$. Thus, the volume increased to $60 \mathrm{l}$, whereas in the tank it was reduced from 119 to $87 \mathrm{l}$. These variations in the capacity entailed changes of about $\pm 18 \%$ in the retention times of both sections. Therefore, an increase of the retention time from 16 to $34 \%$ was observed in the cascade and a decrease from 67 to $49 \%$ was observed in the tank.
The 'pulse experiment' showed results close to the calculated ones. After the first salt injection (basin to tank, Fig. 3A), the first change in conductivity was detected $15 \mathrm{~s}$ after the addition, and it became constant after $40 \mathrm{~s}$, so the retention time was $25 \mathrm{~s}$. In the second injection (tank to basin, Fig. 3B), 29 s were needed to detect a conductivity change, and it was stabilized after $54 \mathrm{~s}$. According to the calculated values, the retention time from the basin to the tank was $20 \mathrm{~s}$, and the retention time from the tank back to the basin was $51 \mathrm{~s}$. This means they only differed from the calculated values by 5 and $3 \mathrm{~s}$, respectively.

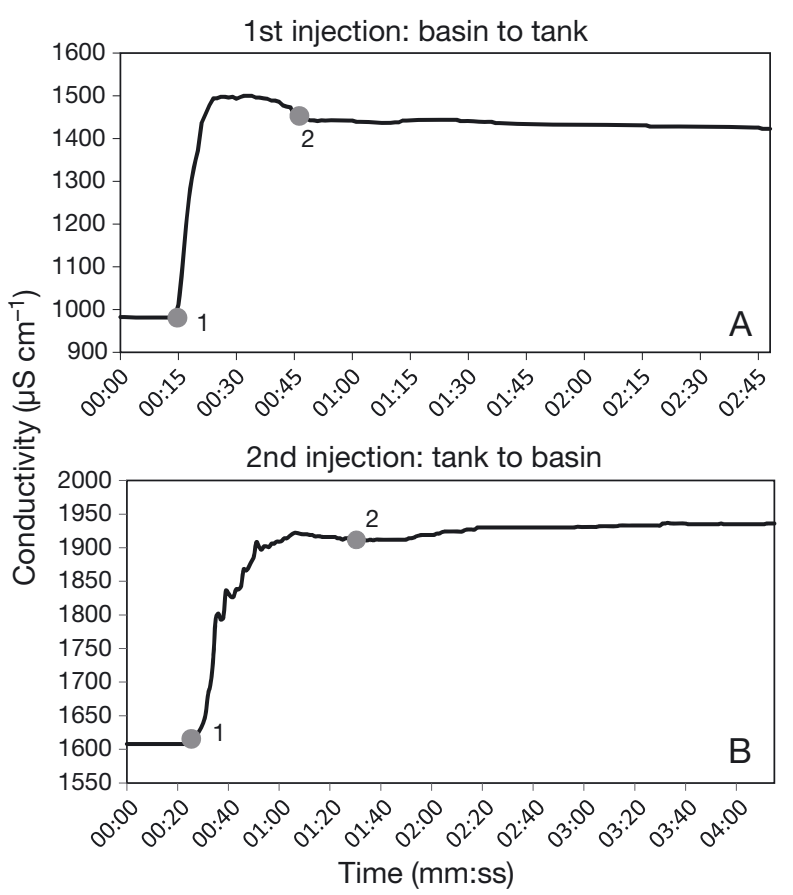

Fig. 3. Pulse experiment. Changes in water conductivity vs. time as result of the 'pulse experiment'. Point 1 indicates the first change in the conductivity; point 2 denotes the beginning of the stabilization. Two injections were conducted:

(A) upper basin to tank and (B) tank to upper basin 


\section{Light conditions and photosynthetic performance}

The highest irradiance of PAR inside the culture (Fig. 4A) was measured in the cascade. When H1 was used, maximum values were 1250, 264 and $11 \mu \mathrm{mol}$ photons $\mathrm{m}^{-2} \mathrm{~s}^{-1}$ in the cascade, basin and tank, respectively. In contrast, when the thickness increased more than 2-fold (H2), a significant decrease in irradiance was detected in the cascade, with maximum irradiance around $600 \mu \mathrm{mol}$ photons $\mathrm{m}^{-2} \mathrm{~s}^{-1}$. Understandably, variations in the basin and tank were not so significant, as the depth remained almost constant in both compartments in $\mathrm{H} 2$, so the
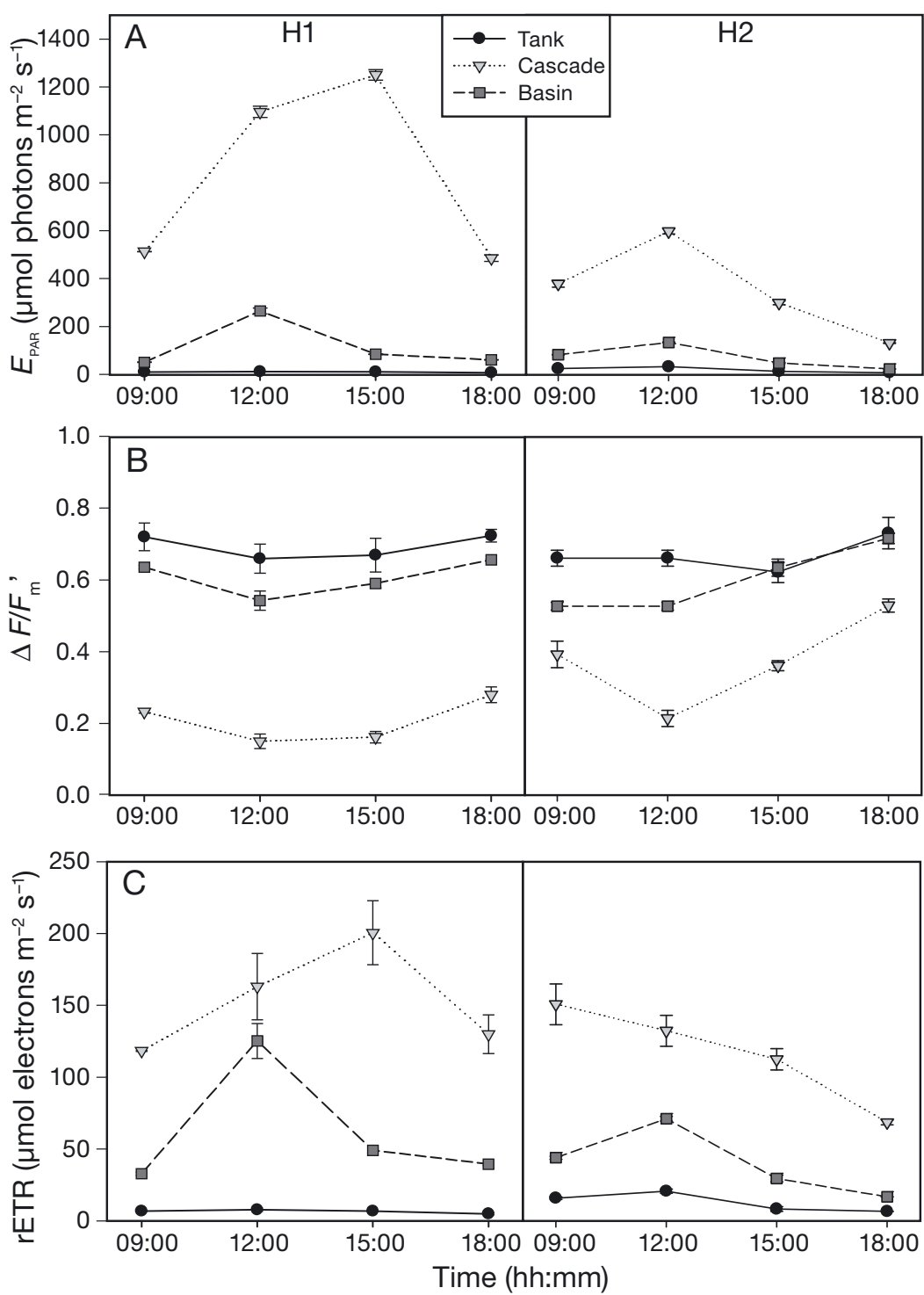

Fig. 4. Diel time-course of irradiance of photosynthetically active radiation $\left(E_{\mathrm{PAR}}\right)$, effective quantum yield $\left(\Delta F / F_{m}{ }^{\prime}\right)$ and relative electron transport rate (rETR) in the tank, cascade and basin using a cascade height of $8 \mathrm{~mm}$ (H1) and $18 \mathrm{~mm}(\mathrm{H} 2)$ light path in both conditions was similar; the depth in the tank was only reduced from 15 to $12 \mathrm{~cm}$, while it was the same in the basin. Changes in the PAR in the cascade area followed a solar daily cycle, showing maximum values at midday, but they were less noticeable in $\mathrm{H} 2$ compared to $\mathrm{H} 1$. Although moderate, the daily cycle could also be observed in the basin, where PAR irradiances ranged between 25 and $264 \mu \mathrm{mol}$ photons $\mathrm{m}^{-2} \mathrm{~s}^{-1}$. Because of the depth of the tank, light did not penetrate far into the suspension, so the total irradiances were low, with little variations throughout the day ( 7 to $33 \mu \mathrm{mol}$ photons $\mathrm{m}^{-2} \mathrm{~s}^{-1}$ ).

As expected, $\Delta F / F_{\mathrm{m}}^{\prime}$ varied inversely with PAR (Fig. 4B). Therefore, the cascade was the section that presented the lowest values, showing increasing $\Delta F / F_{\mathrm{m}}$ ' under low irradiances. A clear daily pattern, in which values were high in the morning, showed a midday depression and then recovered during the afternoon, could be observed in both cases, $\mathrm{H} 1$ and $\mathrm{H} 2$. It is remarkable that the midday depression was shorter when H2 was used: values started to increase after midday, whereas they still remained low at 15:00 h in $\mathrm{H} 1$ conditions. In addition, maximum $\Delta F / F_{\mathrm{m}}{ }^{\prime}$ values were higher in $\mathrm{H} 2$ (around 0.53$)$ than in $\mathrm{H} 1(0.23$ to 0.28$)$. In contrast, values in the basin (0.52 to 0.71 ) were close to those in the tank (0.62 to 0.72$)$ regardless of culture layer thickness. Understandably, daily variations were more significant in the basin and cascade than in the tank because of the drastic decrease of irradiance (close to dark at the bottom of the tank).

The rETR presented daily cycles in agreement with PAR variations in both the cascade and basin (Fig. 4C). It showed higher maximum values in H1 conditions $(200$ and $125 \mu \mathrm{mol}$ electrons $\mathrm{m}^{-2} \mathrm{~s}^{-1}$, in cascade and basin, respectively). As previously pointed out, light penetration into the tank was negligible and rETR remained very low in both $\mathrm{H} 1$ and $\mathrm{H} 2$, ranging from 5 to $33 \mu \mathrm{mol}$ electrons $\mathrm{m}^{-2} \mathrm{~s}^{-1}$. 


\section{Comparison of rETR}

To compare the rETR values among different compartments, values were expressed as a percentage of the total rETR of the system (calculated as the rETR sum of the 3 compartments) (Fig. 5). To take into account the time that the cells spend in each section during a whole cycle, rETR values were weighted using the retention time (\%) shown in Table 1 (i.e. weighted $\mathrm{rETR}=\mathrm{rETR} \times \%$ retention time/100). The same pattern was observed in the distribution of rETR among the different system compartments using both $\mathrm{H} 1$ and $\mathrm{H} 2$. About $20 \%$ took place in the basin, while 70 to $80 \%$ and 4 to $8 \%$ corresponded to the cascade and tank, respectively. This distribution remained constant throughout the day, except at midday, when the contribution of the cascade creased to $55-59 \%$, whereas in the basin it increased up to 42 and $32 \%$ in $\mathrm{H} 1$ and $\mathrm{H} 2$, respectively. When rETR values were weighted, however, we observed different patterns in the distribution of rETR among the compartments related to the use of $\mathrm{H} 1$ or $\mathrm{H} 2$. Although the tank contribution did not change signif- icantly, around 10 to $16 \%$ in both cases, the percentage in the basin decreased (from $14-17 \%$ in $\mathrm{H} 1$ to $7-13 \%$ in $\mathrm{H} 2$ ), while it increased in the cascade (from $70-76 \%$ in $\mathrm{H} 1$ to $80-84 \%$ in H2), which still was the compartment with the highest rETR contribution. The variations observed at midday in non-weighted values were still observed when rETR was weighted: the cascade contribution decreased to $57 \%$, whereas it increased in the basin to $32 \%$ when $\mathrm{H} 1$ was used (no changes were observed in the tank). These changes were less pronounced in $\mathrm{H} 2$ conditions: the percentage in the cascade diminished only to $70 \%$, and it slightly increased in the basin to $13 \%$ (a small increase was detected in the tank to $16 \%$ ). However, whereas the use of the retention time to weight the rETR did not provoke significant changes in the cascade contribution (except at midday in $\mathrm{H} 2$ conditions), it led to changes in the basin and tank contributions which were more significant in $\mathrm{H} 2$ conditions. Whereas the percentage increased in the tank from 3 to $11 \%$ and from 9 to $16 \%$, it decreased in the basin from 42 to $32 \%$ and from 32 to $13 \%$ in $\mathrm{H} 1$ and $\mathrm{H} 2$, respectively.

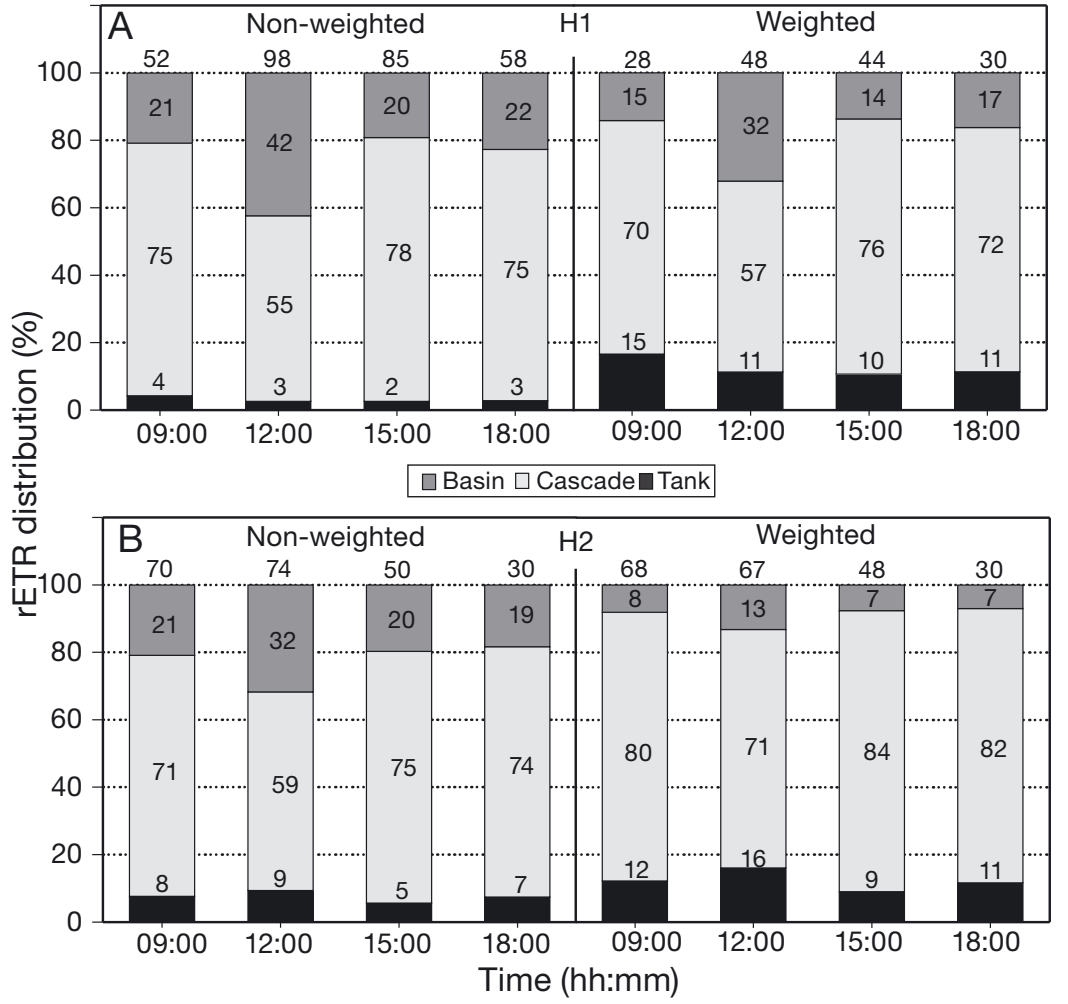

Fig. 5. Distribution of the total relative electron transport rate (rETR) of the system among each compartment. Values in the columns show the rETR in the tank, cascade and basin as \% of the total rETR of the system. Values on the top of the columns indicate the average rETR of the system ( $\mu \mathrm{mol}$ electrons $\mathrm{m}^{-2}$ $\mathrm{s}^{-1}$ ). Weighted values take into account the retention time of the cells in each compartment
In contrast, the average system rETR was calculated for both nonweighted and weighted values at all sampling times as the regular or weighted average, respectively, of the rETR values of the 3 compartments (see top of the columns, Fig. 5). Regarding weighted average values, increasing layer thickness in the cascade (H2) resulted in higher rETR in the morning and midday, although no changes were found during the afternoon. However, a decrease was observed in non-weighted values all day except in the morning. Comparing weighted and non-weighted values using the same layer thickness, we observed that average system rETR was lower in weighted values when H1 was used, whereas they were very similar in $\mathrm{H} 2$ conditions.

As we detected that the average system rETR changed depending on the thickness of the cascade and whether values were weighted or not, we wondered whether and how these changes would be related to the rETR of the compartments. Thus, we calculated the difference between the average system rETR and the rETR 
measured in each compartment to determine how the compartment values differed from the system average rETR when the retention time and/or the cascade thickness were considered. Therefore, in Fig. 6, the rETR measured in each compartment (points) and its difference to the calculated average system rETR (lines) were plotted for each compartment, time of the day and cascade thickness for both weighted and non-weighted values. Non-weighted rETR values presented similar patterns in both $\mathrm{H} 1$ and H2: the rETR in the cascade was always higher
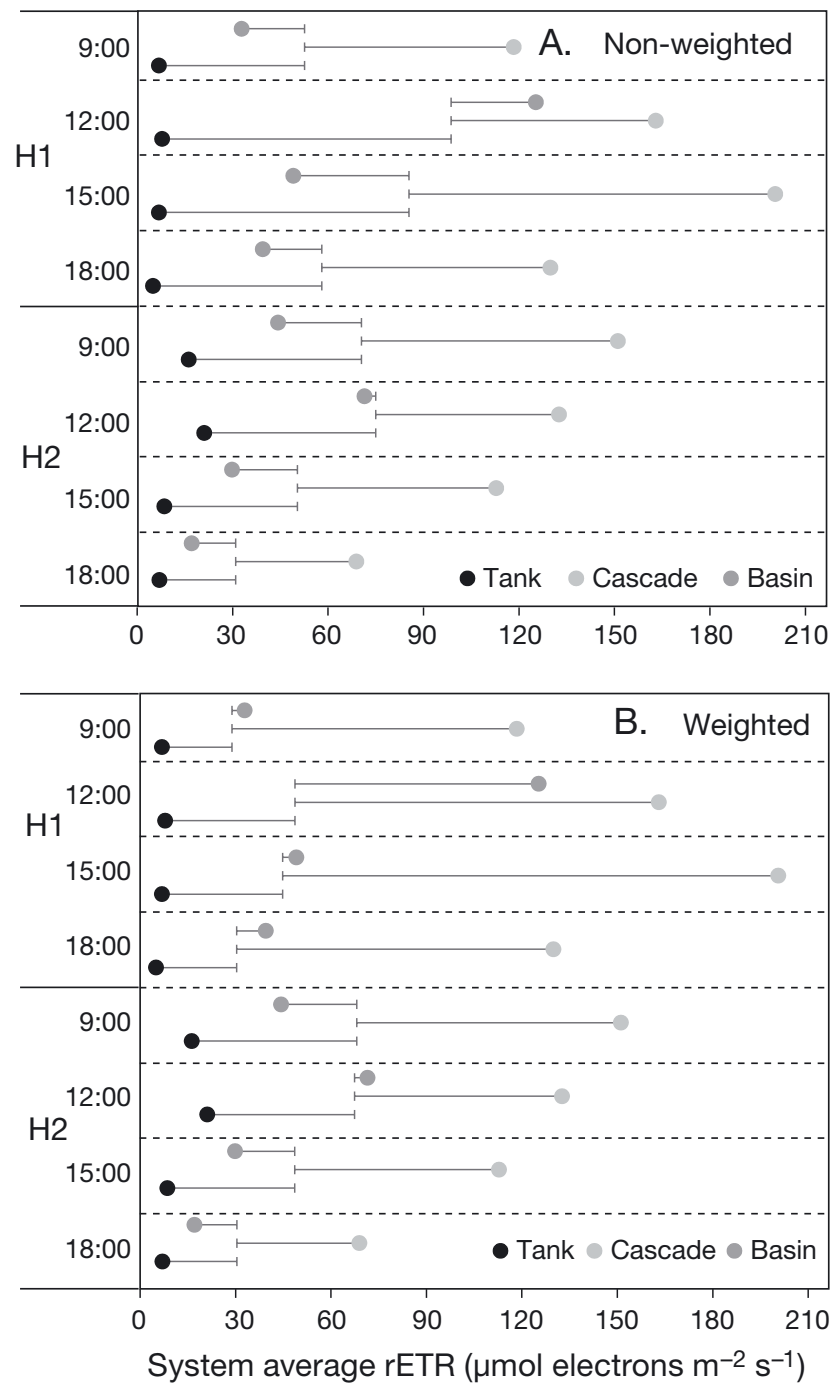

Fig. 6. Difference of the system average rETR vs. the actual values in each compartment. The rETR value of each compartment (points) is given at a particular time of the day and cascade height (H1: $8 \mathrm{~mm}$ and H2: $18 \mathrm{~mm}$ ) in different colors: tank (black), cascade (light grey) and basin (dark grey). Bars indicate the difference between the actual rETR in the tank, cascade and basin and the average rETR of the system. Weighted values take into account the retention time of the cells in each compartment than the average system rETR but was always lower in the basin and tank except in the basin at midday in H1. The weighted average rETR of the system was always higher than that measured in the tank but lower than that of the cascade. Differences were found concerning rETR values in the basin depending on whether $\mathrm{H} 1$ or $\mathrm{H} 2$ was used: while the rETR in the basin was higher than that of the system under $\mathrm{H} 1$ conditions, it remained lower when the height of the cascade increased, except at midday.

\section{DISCUSSION}

Characterization of the photosynthetic performance of the culture in each compartment (upper basin, cascade and tank) of the cultivation unit is essential to improve the light use efficiency in order to increase productivity. Compared to analogous systems (Torzillo et al. 2010, Masojídek et al. 2011), the upper basin situated prior to the main growth compartment, the cascade, is an innovation included in the presented TLC system. Regarding the area exposed to light, both basin and cascade have been taken into account as exposed surface of the system. The basin was designed to facilitate mixing of the suspension after going through the dark phase, but as it is deeper $(30 \mathrm{~mm})$ than the cascade $(8 \mathrm{~mm})$, it also works as a section in which cells acclimate to high irradiance after passing the dark area and before being fully exposed to sunlight in a thin layer on the cascade. For these reasons, and because its depth allows a better placement of instruments (the cascade is not deep enough for probe stability), the basin was the compartment in which online sensors, i.e. PAR and chlorophyll fluorescence, were located in short experiments conducted after this study (Figueroa et al. 2013). In view of the present results, we suggest placing online sensors in the basin to have continuous online measurements of outdoor effective quantum yield and irradiance, which allow the estimation of daily productivity by integrating the area of the rETR vs. the time curve. However, we point out that as one of the goals of this study was to compare the ETR among the different compartments of the system at a given time and as the absorption coefficient $(a$, $\mathrm{m}^{-1}$ ) does not change throughout a whole system cycle (data not shown), rETR values were presented instead of the absolute ones.

Considering that the culture density was low $(1.65 \mathrm{~g}$ dry $w \mathrm{lt}^{-1}$ ) and that the cells were exposed to high irradiances in the cascade, a decrease in the $\Delta F / F_{\mathrm{m}}{ }^{\prime}$ was observed in this compartment, as reported in similar 
systems (Masojídek et al. 2011). This decrease is related to the reduction of the quantum efficiency of the photosynthetic reaction centers. However, when the baffles were used, and the layer of the suspension in the cascade increased to $18 \mathrm{~mm}(\mathrm{H} 2)$, such decrease was attenuated. Under these conditions, values at the beginning and at the end of the day were closer to those achieved in the basin and tank. In addition, variations in the photosynthetic performance of the cascade at midday were evident as changes in its contribution to the overall system rETR: a considerable reduction in the cascade at midday was observed when $\mathrm{H} 1$ was used, although the reduction was not so significant with H2 (see Fig. 5, weighted values). This decrease may be due to photoinhibition processes when the light path in the cascade is short (H1), which causes a decrease in the rETR. Vonshak et al. (1994) and Torzillo et al. $(1996,1998)$ described photoinhibition or down-regulation processes in outdoor cultures of Spirulina under different conditions as being related to damage of the photosynthetic apparatus, which is generally reversible, as a consequence of excessive light. It occurs at light intensities slightly higher than those at which the photosynthetic activity is saturated. Thus, elimination of the photoinhibition or its postponement to higher light intensities can increase microalgal productivity (Torzillo et al. 1998, Chisti 2007). In microalgal biotechnology, there are certain stages of the cultivation process in which the culture density is low, i.e. after inoculation or after harvesting in semi-continuous operation. In these conditions, photoinhibition processes may arise as the culture undergoes changes from low to high light conditions. Therefore, we propose the use of a thicker layer in situations in which culture density is not high enough to avoid photoinhibition. Another strategy could be to operate at higher densities in order to increase the self-shading effect (Grobbelaar 2009b), but this strategy was not tested because it was not among the goals of this study. In high-density cultures, we suggest operating the system at a thinner layer (in our case $8 \mathrm{~mm}$ ), as this setup allows for sufficient turbulence and, subsequently, efficient light use, which is the main advantage of TLC systems.

Concerning the use of retention time to weight rETR values, we suggest the weighted average rETR instead of the regular average (non-weighted values), as it better estimates the overall system productivity, taking into account the volume of the compartments and, thus, the time the cells spend in each one. However, a reduction of 46 to $51 \%$ in the average rETR was observed when values were weighted using H1, while very few differences were found among regular and weighted averages in $\mathrm{H} 2$ conditions (values on top of the columns, Fig. 5). This could be explained because when the thickness was increased to $18 \mathrm{~mm}(\mathrm{H} 2)$, the retention time of the tank was reduced, whereas it increased in the cascade. These changes in the retention time caused variations in the contribution to the average rETR (Fig. 5). When rETR values were weighted, the tank contribution was higher in H1: it increased 65 to $75 \%$ (from $2-4$ to $10-12 \%$ ), whereas it only increased 34 to $42 \%$ (from 5-9 to 9-16\%) in H2. The cascade contribution was lower in H1. It only increased 3 to $8 \%$ (from $55-78$ to $56-75 \%$ ) compared to an increase of 5 to $16 \%$ (from $58-75$ to $70-83 \%$ ) in H2. In addition, these discrepancies in the average rETR could also be illustrated by differences in the rETR measured in each compartment (Fig. 2). rETR in the cascade was lower in $\mathrm{H} 2$ than in $\mathrm{H} 1$, as the measured irradiance inside it decreased with greater thickness. Inside the tank, the measured irradiance slightly increased in $\mathrm{H} 2$, and thus rETR values in this compartment were a bit higher than in $\mathrm{H} 1$.

Retention time in the exposed area (cascade and basin) increased up to $46 \%$ in $\mathrm{H} 2$ compared to $\mathrm{H} 1$ $(28 \%)$. Thus, in $\mathrm{H} 2$ the cells spend almost half of the time of the duration of a system cycle in the exposed area. In spite of this, rETR was higher in the basin and cascade in $\mathrm{H} 1$ than in $\mathrm{H} 2$, which can be related to the reduction of irradiance compared to that in the H1 treatment, as pointed out previously. Lee (2001) reported volumetric productivity at different layer thicknesses in various microalgae, showing an exponential decay with the increase of optical depth, i.e. in cultures in a $1 \mathrm{~cm}$ layer, volumetric productivity was about $4 \mathrm{~g} \mathrm{l}^{-1}$, whereas in a $2 \mathrm{~cm}$ layer, it was $2.5 \mathrm{~g}$ $\mathrm{I}^{-1}$ (a reduction of $37.5 \%$ ). In this study, no reduction was observed in the weighted average rETR or in the volumetric productivity, which remained around 1.6 to $1.8 \mathrm{~g} \mathrm{l}^{-1}$ in both conditions. Indeed, an increase in the optical depth from $\mathrm{H} 1$ to $\mathrm{H} 2$ ( 8 to $18 \mathrm{~mm}$ ) resulted in higher rETR values during the morning (a decrease in the rETR with higher optical depth would have been expected if the culture had been operated at higher densities). Weighted average rETR increased $59 \%$ (from 28 to $68 \mu \mathrm{mol}$ electrons $\mathrm{m}^{-2} \mathrm{~s}^{-1}$ ) and $28 \%$ (from 48 to $67 \mu \mathrm{mol}$ electrons $\mathrm{m}^{-2} \mathrm{~s}^{-1}$ ) at 09:00 and 12:00 $\mathrm{h}$, respectively, whereas in the afternoon, only a slight increase occurred at 15:00 h, and no variation was found at 18:00 h.

Differences between the rETR of the compartments and the system average remained constant regardless of the thickness of the cascade ( $\mathrm{H} 1$ or $\mathrm{H} 2$ ) when the rETR was not weighted. The cascade was the com- 
partment in which values differed the most from the system regular average (Fig. 6A). However, at midday, when the rETR decreased in the cascade, the tank was the area with the most distant values. The weighted average rETR was always higher than the weighted rETR values of each compartment (Fig. 6B). Although it could seem to be an unexpected result, it may be attributed to the high rETR and retention time in the cascade, which consequently resulted in a high contribution of the cascade to the weighted average rETR of the system. These can also be observed comparing $\mathrm{H} 1$ and $\mathrm{H} 2$ conditions: rETR was higher in the cascade at 09:00 and 12:00 $\mathrm{h}$ when $\mathrm{H} 2$ was used, and therefore the weighted average rETR was also higher. At 15:00 and 18:00 $\mathrm{h}$, the rETR was similar in the cascade in both $\mathrm{H} 1$ and H2, so the weighted average was similar as well.

Besides the transition from a high- to a low-light acclimated culture, which is considered a lowfrequency light:dark cycle, other factors such as the rate of mixing, thickness of the culture suspension and the $S / V$ ratio of the system determine high- and medium-frequency fluctuations. A 'flashing light effect', first demonstrated by Kok (1953), is produced by high-frequency fluctuations of light exposure to microalgal cells and is correlated with a high efficiency of energy conversion. High-frequency light: dark cycles have been related to a decrease in the optical depth that resulted in an increase in biomass productivity. Although in this study Chlorella fusca was not operated at very high density, it should be highlighted that densities up to 40-50 $\mathrm{g} \mathrm{l}^{-1}$ have been achieved in other TLC systems (Masojídek et al. 2011). Therefore, it would be worth investigating the occurrence of light:dark cycles in these systems, as they could be important in the case of very dense cultures. For example, studies aimed to reduce the optical path of the cascade to shorten the time that the cells spend in the dark portion of the reactor would provide information about how light:dark cycles could be related to an increase in biomass productivity.

In addition, medium-frequency fluctuations could also have an effect on biomass productivities, which are mainly related to variations in the $S / V$ ratio (Grobbelaar 1989, Janssen et al. 2000). Higher biomass productivities are expected in systems with higher $S / V$ ratios (Masojídek et al. 2011, Figueroa et al. 2013), which points out the importance of minimizing the dark volume in the system. Comparison of different TLC units demonstrates the importance of the $S / V$ ratio in the system rETR. The central European location of Třebon (southern part of the Czech Republic) has a relatively short annual cultivation season. Preliminary calculations indicate that TLC units placed there would be superior to other systems if located in climatically favorable locations and if constructed at low cost (Borowitzka 1999). Figueroa et al. (2013) compared the productivities of both TLCs, the experimental unit placed in Třeboň and characterized by Masojídek et al. (2011) $(S / V$ ratio = 100 to $135 \mathrm{~m}^{-1}$ ) and the system described in this study $\left(S / V\right.$ ratio $\left.=22.47 \mathrm{~m}^{-1}\right)$. The productivity reported for the first system was lower than that reported for the latter one. Therefore, it was concluded that higher $S / V$ ratios were related to higher productivities. Nevertheless, despite that the TLC system used in this study has an $S / V$ ratio $79 \%$ lower than that used by Masojídek et al. (2011), only a $37 \%$ reduction in biomass productivity was observed. In our system, the culture spent a long time in the tank (66 and $48 \%$ in $\mathrm{H} 1$ and $\mathrm{H} 2$, respectively), which significantly limited productivity, although it contributed only 4 to $8 \%$ of the total ETR of the system. Therefore, a strong reduction of the retention time in the tank would be necessary by modifying its geometry or by operating the tank at the minimum volume possible. As pointed out in the 'Materials and methods' section, we used this last strategy (minimum tank volume) in order to operate the system at the maximum $S / V$ ratio so it could achieve higher productivities.

The TLC system described in this study could be used for purposes other than as an open cultivation unit for microalgae production and photobiological studies, i.e. correlation to potential lipid or protein productivity by modification of light quality and quantity. In the natural environment, radiation fluctuations produce varied effects ranging from an increase (Marra 1978) to a decrease (Kroon et al. 1992) to no change (Yoder \& Bishop 1985) in phytoplankton primary productivity. The modulation of both PAR and UVR could have a positive effect on the accumulation of fatty acids to be used as functional food (Adarme-Vega et al. 2012) or for the production of biodiesel (Sharma et al. 2012). Thus, this system could also be used to conduct experiments to evaluate the effects of light regime on photosynthetic activity and accumulation of high-value compounds.

In conclusion, some advantages of the TLC system can be highlighted compared to other open systems, and some considerations in its operation can be used for other units. The increase of the layer thickness in the cascade seems to be a good option in those conditions in which culture density is not high enough to avoid photoinhibition. We suggest the consideration of the retention time to estimate the average rETR of the system since it better estimates the overall system 
productivity (it takes into account the volume of the compartments) and thus the time the cells spend in each one. These considerations would contribute to more accurate determinations of rETR, which could become a helpful tool to monitor photosynthetic activity in microalgae mass cultures in TLCs. The enhancement of the photosynthetic efficiency would be advantageous in order to achieve low-cost microalgal production for biotechnological purposes.

Acknowledgements. This study was supported by the government of Spain (Project Ecolife CGL08-05407-C03-01) and Junta de Andalucía (research group Photobiology and Biotechnology of Aquatic Organisms, RNM-295). The 9th International GAP Workshop was financed by the Action CTM2011-15659-E (Ministry of Economy and Competitiveness). C.G.J. thanks the FPU Grant of the Ministry of Education of Spain. The authors thank David López, a member of the Unit of Photobiology of the University of Málaga, for his technical assistance. J.M. was also supported by the Ministry of Education, Youth and Sports of the Czech Republic, project Algatech CZ.1.05/2.1.00/03.0110.

\section{LITERATURE CITED}

Adarme-Vega TC, Lim DKY, Timmins M, Vernen F, Li Y, Schenk PM (2012) Microalgal biofactories: a promising approach towards sustainable omega-3 fatty acid production. Microb Cell Fact 11:96

Andersen RA, Berges JA, Harrison PF, Watanabe MM (2005) Recipes for freshwater and seawater media. In: Andersen RA (ed) Algal culturing techniques. Elsevier Academic Press, London, p 429-538

- Baker NR (2008) Chlorophyll fluorescence: a probe of photosynthesis in vivo. Annu Rev Plant Biol 59:89-113

Bischoff HW, Bold HC (1963) Phycological studies. IV. Some algae from Enchanted Rock and related algal species. University of Texas Publication 6318, Austin, TX

> Borowitzka MA (1999) Commercial production of microalgae: ponds, tanks, tubes and fermenters. J Biotechnol 70:313-321

> Brányiková I, Maršálková B, Doucha J, Brányik T, Bišová K, Zachleder V, Vítová M (2011) Microalgae-novel highly efficient starch producers. Biotechnol Bioeng 108:766-776

Chinnasamy S, Bhatnagar A, Hunt RW, Das KC (2010) Microalgae cultivation in a wastewater dominated by carpet mill effluents for biofuel applications. Bioresour Technol 101:3097-3105

Chisti Y (2007) Biodiesel from microalgae. Biotechnol Adv 25:294-306

Dubinsky Z, Falkowski PG, Wyman K (1986) Light harvesting and utilization by phytoplankton. Plant Cell Physiol 27:1335-1349

> Falkowski PG, Gan R, Wyman K (1985) Growth-irradiance relationships in phytoplankton. Limnol Oceanogr 30: 311-321

> Figueroa FL, Jerez CG, Korbee N (2013) Use of in vivo chlorophyll fluorescence to estimate photosynthetic activity and biomass productivity in microalgae grown in different culture systems. Lat Am J Aquat Res 41: 801-819
Genty B, Briantais JM, Baker NR (1989) The relationship between the quantum yield of photosynthetic electrontransport and quenching of chlorophyll fluorescence. Biochim Biophys Acta 990:87-92

- Ghirelli F, Leckner B (2004) Transport equation for the local residence time of a fluid. Chem Eng Sci 59:513-523

Grima EM, Fernández Sevilla JM, Acién Fernández FG (2010) Microalgae, mass culture methods. In: Flickinger MC (ed) Encyclopedia of industrial biotechnology: bioprocess, bioseparation, and cell technology. John Wiley \& Sons, New York, NY, p 1-24

> Grobbelaar JU (1989) Do light/dark cycles of medium frequency enhance phytoplankton productivity? J Appl Phycol 1:333-340

> Grobbelaar JU (1994) Turbulence in mass algal cultures and the role of light/dark fluctuations. J Appl Phycol 6: 331-335

> Grobbelaar JU (2009a) Factors governing algal growth in photobioreactors: the 'open' versus 'closed' debate. J Appl Phycol 21:489-492

Grobbelaar JU (2009b) Upper limits of photosynthetic productivity and problems of scaling. J Appl Phycol 21: 519-522

> Grobbelaar JU (2010) Microalgal biomass production: challenges and realities. Photosynth Res 106:135-144

> Grobbelaar JU (2012) Microalgae mass culture: the constraints of scaling-up. J Appl Phycol 24:315-318

> Grobbelaar JU, Nedbal L, Tichý V (1996) Influence of high frequency light/dark fluctuations on photosynthetic characteristics of microalgae photoacclimated to different light intensities and implications for mass algal cultivation. J Appl Phycol 8:335-343

> Ihnken S, Beardall J, Kromkamp J, Gómez Serrano C and others (2014) Light acclimation and pH perturbations affect photosynthetic performance in Chlorella mass culture. Aquat Biol 22:95-110

Janssen M, de Winter M, Tramper J, Mur LR, Snel J, Wijffels RH (2000) Efficiency of light utilization of Chlamydomonas reinhardtii under medium-duration light/dark cycles. J Biotechnol 78:123-137

Kok B (1953) Experiments on photosynthesis by Chlorella in flashing light. In: Burlew JS (ed) Algal culture: from laboratory to pilot plant. Carnegie Institution of Washington Publication 600, Washington, DC, p 63-75

> Kromkamp JC, Dijkman NA, Peene J, Simis SGH, Gons HJ (2008) Estimating phytoplankton primary production in Lake IJsselmeer (The Netherlands) using variable fluorescence (PAM-FRRF) and C-uptake techniques. Eur J Phycol 43:327-344

- Kromkamp JC, Forster RM (2003) The use of variable fluorescence measurements in aquatic ecosystems: differences between multiple and single turnover measuring protocols and suggested terminology. Eur J Phycol 38: 103-112

- Kroon BMA, Latasa M, Ibelings BW, Mur LR (1992) The effect of dynamic light regimes on Chlorella. I. Pigments and cross sections. Hydrobiologia 238:71-78

> Lee YK (2001) Microalgal mass culture systems and methods: their limitation and potential. J Appl Phycol 13: 307-315

> Li Y, Chen YF, Chen P, Min M and others (2011) Characterization of a microalga Chlorella sp. well adapted to highly concentrated municipal wastewater for nutrient removal and biodiesel production. Bioresour Technol 102:5138-5144 
Malpartida I, Jerez CG, Morales MM, Nascimiento P and others (2014) Synergistic effect of UV radiation and nutrient limitation on Chlorella fusca (Chlorophyta) cultures grown in outdoor cylindrical photobioreactors. Aquat Biol 22:141-158

Markou G, Nerantzis E (2013) Microalgae for high-value compounds and biofuels production: a review with focus on cultivation under stress conditions. Biotechnol Adv 31:1532-1542

> Marra J (1978) Phytoplankton photosynthetic response to vertical movement in a mixed layer. Mar Biol 46: 203-208

Masojídek J, Prášil O (2010) The development of microalgal biotechnology in the Czech Republic. J Ind Microbiol Biotechnol 37:1307-1317

Masojídek J, Kopecký J, Giannelli L, Torzillo G (2011) Productivity correlated to photobiochemical performance of Chlorella mass cultures grown outdoors in thin-layer cascades. J Ind Microbiol Biotechnol 38:307-317

Mulbry W, Kondrad S, Pizarro C, Kebede-Westhead E (2008) Treatment of dairy manure effluent using freshwater algae: algal productivity and recovery of manure nutrients using pilot-scale algal turf scrubbers. Bioresour Technol 99:8137-8142

Muller-Feuga A (2000) The role of microalgae in aquaculture: situation and trends. J Appl Phycol 12:527-534

Pulz O (2001) Photobioreactors: production systems for phototrophic microorganisms. Appl Microbiol Biotechnol 57:287-293

Schreiber U, Schliwa U, Bilger W (1986) Continuous recording of photochemical and non-photochemical chlorophyll fluorescence quenching with a new type of modulation fluorometer. Photosynth Res 10:51-62

Schreiber U, Hormann H, Neubauer C, Klughammer C (1995) Assessment of photosystem II photochemical quantum yield by chlorophyll fluorescence quenching analysis. Aust J Plant Physiol 22:209-220

Šetlík I, Sust V, Málek I (1970) Dual purpose open circulation units for large scale culture of algae in temperate zones. I. Basic design considerations and scheme of a pilot plant. Algol Stud 1:111-164

Sforza E, Simionato D, Giacometti GM, Bertucco A, Moro-

Submitted: December 9, 2013; Accepted: September 4, 2014 sinotto T (2012) Adjusted light and dark cycles can optimize photosynthetic efficiency in algae growing in photobioreactors. PLoS ONE 7:e38975

Sharma KK, Schuhmann H, Schenk PM (2012) High lipid induction in microalgae for biodiesel production. Energies 5:1532-1553

Spolaore P, Joannis-Cassan C, Duran E, Isambert A (2006) Commercial applications of microalgae. J Biosci Bioeng 101:87-96

Suggett DJ, Moore CM, Geider RJ (2010) Estimating aquatic productivity from active fluorescence measurements. In: Suggett DJ, Prášil O, Borowitzka MA (eds) Chlorophyll a fluorescence in aquatic sciences: methods and applications. Springer, Dordrecht, p 103-127

> Terry KL (1986) Photosynthesis in modulated light: quantitative dependence of photosynthetic enhancement on flashing rate. Biotechnol Bioeng 28:988-995

Torzillo G, Accolla P, Pinzani E, Masojidek J (1996) In situ monitoring of chlorophyll fluorescence to assess the synergistic effect of low temperature and high irradiance stresses in Spirulina cultures grown outdoors in photobioreactors. J Appl Phycol 8:283-291

> Torzillo G, Bernardini P, Masojídek J (1998) On-line monitoring of chlorophyll fluorescence to assess the extent of photoinhibition of photosynthesis induced by high oxygen concentration and low temperature and its effect on the productivity of outdoor cultures of Spirulina platensis (Cyanobacteria). J Phycol 34:504-510

Torzillo G, Gianelli L, Martínez-Roldán AJ, Verdone N, De Filippis P, Scarsella M, Bravi M (2010) Microalgae culturing in thin-layer photobioreactors. Chem Eng Trans 20: 265-270

> Tredici MR (2010) Photobiology of microalgae mass cultures: understanding the tools for the next green revolution. Biofuels 1:143-162

> Vonshak A, Torzillo G, Tomaseli L (1994) Use of chlorophyll fluorescence to estimate the effect of photoinhibition in outdoor cultures of Spirulina platensis. J Appl Phycol 6: 31-34

- Yoder JA, Bishop SS (1985) Effects of mixing-induced irradiance fluctuations on photosynthesis of natural assemblages of coastal phytoplankton. Mar Biol 90:87-93

Proofs received from author(s): October 16, 2014 